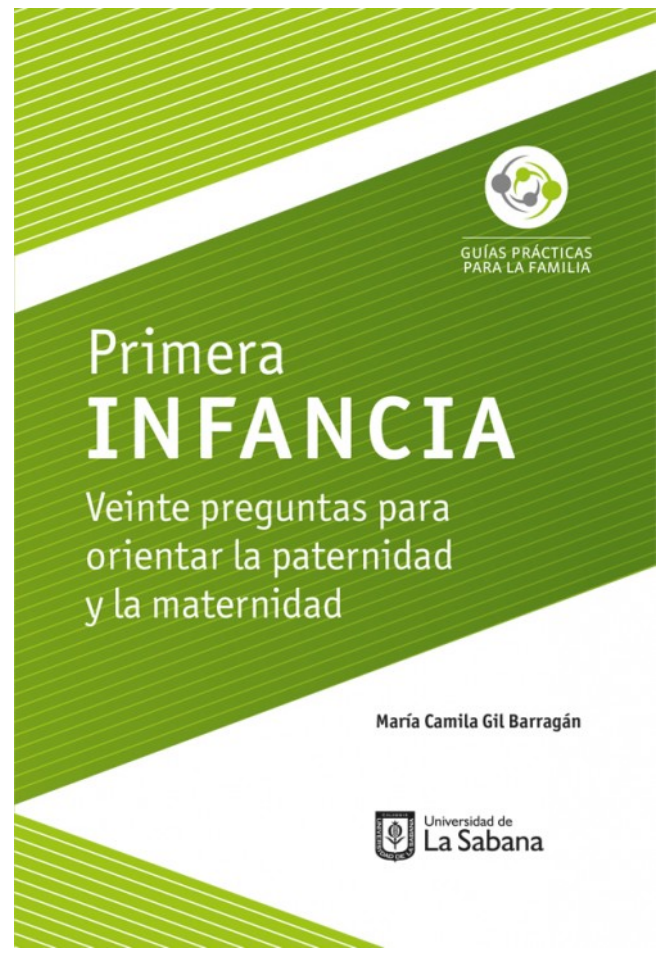

\title{
PRIMERA INFANCIA \\ VEINTE PREGUNTAS PREGUNTAS PARA ORIENTAR LA \\ PATERNIDAD Y LA MATERNIDAD
}

Por: María Camila Gil Barragán

Formato: Impreso

ISBN: 978-958-12-0461-8

Facultad: Instituto de la Familia

Colección: Guías prácticas para la Familia

DOI: https://doi.org/10.5294/978-958-12-0461-8

Idioma: Español

Precio en dólares: USD $\$ 8,00$

Número de páginas: 80

Palabras clave: Educación familiar, Educación primaria, Familia, Infancia, Padres e hijos

\section{$\$ 22.000$}

\section{Reseña del Producto}

La primera infancia es una etapa fundamental para el adecuado desarrollo del ser humano. De acuerdo con el Código de la Infancia y la Adolescencia de Colombia (Ley 1098 de 2006), la primera infancia comprende la etapa del ciclo vital desde los cero hasta los seis años de edad. Numerosos estudios científicos han demostrado cómo esta es la etapa más importante para el desarrollo humano, puesto que es en estos primeros años de vida en los que se forma la mayoría de las conexiones neuronales que la persona tendrá a lo largo de su vida: la sociabilidad, el lenguaje, la motricidad, la capacidad de amar

\section{Información Adicional}

Peso: $1 \mathrm{~kg}$

Tamaño: $17 \times 24 \times 2 \mathrm{~cm}$

Sku: 9789581204618

Código topografico: 372.21

\section{Tabla de contenido}

\section{INTRODUCCIÓN}

VEINTE PREGUNTAS PARA ORIENTAR LA PATERNIDAD Y LA MATERNIDAD DURANTE LA PRIMERA INFANCIA

1. ¿Cómo se da el desarrollo del niño en los primeros seis años de vida?

2. ¿Qué se debe educar en la primera infancia?

3. ¿Qué virtudes educar en la primera infancia?

4. ¿Cuál es la clave de la educación en la primera infancia?

5. ¿Cómo amar efectivamente a mi hijo?

6. ¿Cuál es el estilo parental idóneo para educar a mi hijo?

7. ¿Cómo poner límites durante la primera infancia?

8. ¿Qué hacer cuando se incumplen las normas? 
9. ¿Qué hacer ante las pataletas? 35

10. ¿Cómo educar la inteligencia emocional de mi hijo?

11. ¿Cómo ayudarle a dejar el pañal? 41

12. ¿Cuál es la mejor forma para quitarle el tetero?

13. ¿Cómo planear, preparar y afrontar el ingreso del hijo al jardín o al colegio?

14. ¿Cómo debe ser la relación entre los padres y el jardín o colegio?

15. ¿Cómo preparar al hijo para la llegada de su hermanito?

16. ¿Cuál debe ser el acceso de los hijos en la primera infancia a las tecnologías de la información y la comunicación (TIC)?

17. ¿Cómo educar el hábito alimenticio en los hijos?

18. ¿Cómo educar el amor a la lectura en la primera infancia?

19. ¿Cuál es la importancia del juego en la primera infancia?

20. ¿Cuál es el mejor regalo que los padres pueden darle a su hijo?

REFERENCIAS 